\title{
Antihyperglycemic effect of short-term arginyl-fructose supplementation in subjects with prediabetes and newly diagnosed type 2 diabetes: randomized, double-blinded, placebo-controlled trial
}

Su Eun Park ${ }^{1+}$, Ok-Hwan Kim ${ }^{3+}$, Jung Hyun Kwak ${ }^{1,2}$, Kwang-Hyoung Lee $^{3}$, Young-In Kwon ${ }^{4}$, Kwang Hoe Chung ${ }^{3^{*}}$ and Jong Ho Lee (2* $^{1,}$

\begin{abstract}
Background: A previous study reported that arginyl-fructose may have great value as a functional food with antioxidant and antidiabetic activities. However, there have been few clinical studies on the efficacy of arginyl-fructose supplementation for blood glucose control.

Methods: In this double-blind, placebo-controlled study, 60 Korean subjects with prediabetes or type 2 diabetes mellitus were randomly assigned to placebo or test groups. The test group subjects received $1500 \mathrm{mg} /$ day arginyl-fructose. Fasting serum levels of glucose, hemoglobin A1c, insulin, and free fatty acids were measured by 2-hour oral glucose tolerance tests at baseline and after the 6-week intervention. Eleven subjects dropped out or were excluded during the trial. The data for the remaining 49 were statistically analyzed using Student's $t$-test and paired $t$-test.
\end{abstract}

Results: After the 6-week intervention, the test group showed significant reductions in serum glucose levels at 30 minutes $(-19.4 \pm 5.62 \mathrm{mg} / \mathrm{dL})$ and 60 minutes $(-15.4 \pm 7.01 \mathrm{mg} / \mathrm{dL})$ and reduced glucose area under the curve $(-27.4 \pm 8.59 \mathrm{mg} / \mathrm{dL})$ compared with those of the placebo control group. The changes (differences from baseline) in serum glucose levels at 60 minutes and glucose area under the curve in the test group differed significantly from those in the control group even after adjusting for baseline values. In contrast, glucose-related biomarkers including hemoglobin A1c, insulin, and C-peptide levels were not significantly improved by the dietary intervention with arginyl-fructose.

Conclusions: Arginyl-fructose supplementation (1500 mg/day) may be beneficial for reducing postprandial blood glucose levels in patients with prediabetes or type 2 diabetes mellitus.

Trial registration: ClinicalTrials.gov NCT02285231. Registered 11 May 2014.

Keywords: Glucose control, Prediabetes, Arginyl-fructose, Supplementation

\footnotetext{
*Correspondence: hoe@cha.ac.kr; jhleeb@yonsei.ac.kr

${ }^{\dagger}$ Equal contributors

${ }^{3}$ R\&D Center, CHA BioMed and Department of Applied Science, CHA University, Gyeonggi-do 463-836, Republic of Korea

'Department of Food and Nutrition, National Research Laboratory for Clinical

Nutrigenetics/Nutrigenomics, Yonsei University, Seoul 120-749, Republic of

Korea

Full list of author information is available at the end of the article
}

C Biomed Central

(c) 2015 Park et al. Open Access This article is distributed under the terms of the Creative Commons Attribution 4.0 International License (http://creativecommons.org/licenses/by/4.0/), which permits unrestricted use, distribution, and reproduction in any medium, provided you give appropriate credit to the original author(s) and the source, provide a link to the Creative Commons license, and indicate if changes were made. The Creative Commons Public Domain Dedication waiver (http://creativecommons.org/publicdomain/zero/1.0/) applies to the data made available in this article, unless otherwise stated. 


\section{Background}

The prevalence of diabetes continues to increase globally. The number of people with diabetes is predicted to increase to 366 million in 2030 [1, 2]. The 2012 Korean National Health and Nutrition Survey indicates that the prevalence of diabetes mellitus and impaired fasting glucose (IFG) were 11.8 and $22.2 \%$, respectively, in Korean adults ( $\geq 30$ years old). In Korea, the number of people with IFG and impaired glucose tolerance (IGT), which are prediabetic conditions, is increasing every year [3].

Many foods and supplements have been reported to promote normal glucose control. Korean red ginseng (KRG; Panax ginseng C.A. Meyer) is a well-known traditional oriental medicine and tonic [4]. Red ginseng is processed for use by steaming and drying raw ginseng. One of the processing steps involves a nonenzymatic browning reaction called a Maillard reaction. Arginyl-fructose (AF) and arginyl-fructosyl-glucose (AFG) are major Amadori rearrangement compounds formed during the early stage of the Maillard reaction from arginine and glucose or arginine and maltose, respectively [5].

Arginine is a primary amino acid constituent of ginseng. Amino acid derivatives such as AF and AFG are widely distributed in KRG [5-7]. Previous studies reported that commercial red ginseng products could have AF and AFG levels ranging from $0.35-2.51 \%$ and $0.25-2.64 \%$, respectively $[8,9]$. The ginsenosides, which are betterknown KRG components, have a content ranging from $0.5-1.1 \%[8,10]$.

Many studies have evaluated the pharmacological effects of AF and AFG. One study reported that AF and AFG have antihyperglycemic effects in vitro and in vivo. These Amadori rearrangement compounds (AF and AFG) significantly reduced postprandial blood glucose levels after starch or sucrose loading in rats. AF and AFG displayed mild inhibitory activity against pancreatic $\alpha$ amylase [8] and moderate levels of cellular antioxidant activity [11]. Although AF and AFG have potential as pharmacological agents for glycemic control, there are no clinical trials assessing the effects of AF and AFG on blood glucose regulation.

Our study is the first evaluation of AF supplementation for glycemic control in humans. Our previous study indicated that KRG supplementation was efficacious for glucose control [12]. Therefore, we applied a similar study design for this randomized, double-blind, and placebo-controlled clinical trial to evaluate the effect of AF supplementation on blood glucose control in subjects with IFG, IGT, or newly diagnosed type 2 diabetes mellitus (T2DM). This study establishes clinical evidence for the effect of AF on blood glucose control.

\section{Methods}

\section{Subjects and study design}

Study participants aged 20-70 years old were recruited by advertisements in a local newspaper. All subjects were evaluated as prediabetic (IFG or IGT) or were newly diagnosed with T2DM and not taking any hyperglycemic medicine. We measured fasting glucose levels from oral glucose tolerance tests (OGTTs; $75 \mathrm{~g}$ oral glucose) at 2hour time points, and confirmed diagnoses of T2DM, IFG, or IGT. Prediabetes was defined as having a serum glucose level 100-125 mg/dL (IFG) or 2-hour OGTT value 140-199 mg/dL (IGT). The T2DM diagnosis was defined as fasting plasma glucose $\geq 126 \mathrm{mg} / \mathrm{dL}$ and 2-hour OGTT value $\geq 200 \mathrm{mg} / \mathrm{dL}$. Subjects were excluded if they had any diagnosis of renal disease, liver disease, chronic inflammatory disease, chronic alcoholism, consumed any health-related functional food, were pregnant, were breast-feeding, or were taking glucose-lowering medications or insulin injections. After the glucose screening test and evaluation of exclusion criteria, subjects with IFG, IGT, or newly diagnosed T2DM were enrolled in this study. Sixty subjects (20-70 years old) with IFG, IGT, or T2DM gave written informed consent for enrollment in this study, which was approved by the Institutional Review Board of Yonsei University. The study is registered at ClinicalTrials.gov (trial number NCT02285231).

$\mathrm{AF}$ and placebo were both provided by $\mathrm{CHA}$ BioMed Co., Ltd (Gyeonggi-do, Korea). AF was manufactured by heat treatment of food-grade arginine and glucose, which were mixed, stirred for 1 hour at $80{ }^{\circ} \mathrm{C}$, and subjected to spray drying. Participants in the test group received one AF tablet per day $(1500 \mathrm{mg} /$ day $)$. The placebo group received one tablet containing baked barley powder per day $(1500 \mathrm{mg} /$ day). This study was designed as a 6-week randomized, double-blinded, placebo-controlled trial. Sixty subjects were randomly assigned to receive placebo $(n=30)$ or $\operatorname{AF}(n=30)$. The participants were randomized in a $1: 1$ ratio for the intervention or the placebo group. Both groups consumed two capsules, three times daily, for a total of six capsules consumed per day. Subjects met with the investigational team at three different time points: during screening (week -2), during randomization and treatment baseline (week 0), and at the treatment end-point (week 6). All participants were encouraged to maintain their usual lifestyle and dietary habits and to keep a food record. Compliance was assessed by counting the remaining tablets at week 6 and by evaluating the food records. If more than $80 \%$ of the tablets were consumed, compliance was considered to be acceptable.

\section{Sample size calculation}

Previous research on the effects of glucose-related functional foods on patients with IFG, IGT, or T2DM reported a $19.24 \pm 2.86 \mathrm{mg} / \mathrm{dL}$ ( \pm standard deviation $(\mathrm{SD})$ ) reduction 
in OGTT glucose levels at 120 minutes compared with placebo effects. We hypothesized that a similar reduction in OGTT glucose levels at 120 minutes would be observed after AF treatment among the target population in this study, which is considered clinically meaningful [13]. Power analysis indicated that a total sample of 40 subjects, 20 in each group, would be required to detect a $19.24 \mathrm{mg} / \mathrm{dL}$ reduction in glucose at 120 minutes, with a significance level of 0.05 and at least $80 \%$ power. We factored in a $30 \%$ dropout rate to determine a recruitment target of 58 study subjects.

\section{Dietary intervention and assessment of dietary intake/ physical activity level}

The diet information for the subjects was obtained using both a 24-hour recall method and a semiquantitative food frequency questionnaire that had been previously validated [14]. We used the former for analyses and the latter to check if the 24-hour recall method yielded representative data for the usual dietary pattern. All subjects were given written and verbal instructions by a dietitian on how to complete 3-day ( 2 weekdays and 1 weekend day) dietary records every week throughout the study period. For the dietary records, subjects were instructed to weigh and record the food amounts before ingestion and any food remaining after ingestion. The dietician checked participants' compliance via biweekly telephone interviews during the intervention period. Participants were interviewed to discern whether they were complying with the study instructions, including AF supplement consumption, dietary intake, and weight change. Dietary energy values and nutrient contents from the 3-day food records were calculated using the Computer Aided Nutritional analysis program (CAN-pro 3.0, Korean Nutrition Society, Seoul, Korea). Total energy expenditure (kcal/day) was calculated from activity patterns including basal metabolic rate, physical activity for 24 hours [15], and specific food dynamic action. The basal metabolic rate for each subject was calculated with the HarrisBenedict equation [16].

\section{Anthropometric parameters, blood pressure measurements, and blood collection}

Body weight and height were measured in the morning with the subjects unclothed and without shoes. Body mass index (BMI) was calculated as body weight in $\mathrm{kg}$ divided by height in meters squared $\left(\mathrm{kg} / \mathrm{m}^{2}\right)$. Body composition was determined by a foot-to-foot bioelectrical impedance analyzer while the subject was standing erect with bare feet on the analyzer footpads (Tanita, Japan); the analyzer was used to obtain lean body mass $(\mathrm{kg})$, fat mass $(\mathrm{kg})$, and body fat (\%). Blood pressure was measured after a 10-minute rest using the left arm of the seated patient with an automatic blood pressure monitor
(TM-2654, A\&D, Tokyo, Japan). The mean of two measurements was recorded for each subject. Venous blood specimens were collected in EDTA-treated and plain tubes after a 12-hour fast. The tubes were placed on ice until they arrived at the laboratory (within 1-3 hours), where they were centrifuged into plasma or serum and then stored at $-70{ }^{\circ} \mathrm{C}$ until analysis.

\section{Glucose, insulin, and C-peptide concentrations}

Fasting glucose was determined using the glucose oxidase method with a Beckman Glucose Analyzer (Beckman Instruments, Irvine, CA, USA). Insulin was determined by radio-immunoassay using commercial kits from ImmunoNuclear Corporation (Stillwater, MN, USA). C-peptide concentration was determined by two-site sandwich immunoassay using an ADVIA Centaur XP Immunoassay system (Siemens, USA).

\section{Oral glucose tolerance test}

Subjects drank a 75-g glucose solution after an overnight fast. Venous blood specimens were collected before and 30,60 , and 120 minutes after glucose ingestion. Glucose was determined using the glucose oxidase method with the Beckman Glucose Analyzer (Beckman Instruments).

\section{Serum lipid profile and apolipoprotein A-I and B}

Fasting serum concentrations of total cholesterol and triglyceride (TG) were measured using commercially available kits and the Hitachi 7150 Autoanalyzer (Hitachi Ltd., Tokyo, Japan). High-density lipoprotein (HDL) was measured from the supernatant using enzymatic methods. Low-density lipoprotein (LDL) was estimated indirectly for subjects with serum TG levels $<400 \mathrm{mg} / \mathrm{dL}$ using the Friedewald formula. For subjects with serum TG concentrations $\geq 400 \mathrm{mg} / \mathrm{dL}$, LDL was determined directly using an enzymatic method and the Hitachi 7150 Autoanalyzer. Serum apolipoprotein (apo) A-I and apo B were determined using turbidimetry at $340 \mathrm{~nm}$ using a specific antiserum (Roche, Switzerland).

\section{Statistical analyses}

Statistical analyses were computed with SPSS v. 18.0 for Windows (SPSS Inc., Chicago, IL, USA). Each variable was examined for normal distribution, and significantly skewed variables were subjected to log transformation. For descriptive purposes, mean values of untransformed and unadjusted variables are presented. Baseline characteristics and comparisons between the intervention and control groups were evaluated using the Student's $t$-test for continuous variables. A paired $t$-test was used to evaluate the effects of AF or placebo within each group before and after the intervention. Only those results from participants who completed the intervention program were analyzed $(n=49)$. Results are expressed as mean \pm standard error 
of the mean (SEM). A $p$-value $<0.05$ was considered statistically significant.

\section{Results}

\section{Characteristics of study participants}

Among the enrolled subjects $(n=60), 11$ subjects dropped out and 49 subjects completed the study. Study participant were included in the trial from January 2014 to May 2014. One of the 11 dropout subjects was in the test group and was excluded due to the consumption of glucose-related medicine during the trial. Three subjects in the test group and two subjects in the placebo group dropped out due to large weight changes (more than $\pm 2 \mathrm{~kg}$ ) during the trial. Five subjects (one from the test group and four from the placebo group) were excluded for suboptimal compliance with ingesting $\mathrm{AF}$ (consuming $<80 \%$ of the instructed amount). Finally, 49 participants (test group, 25; placebo group, 24) completed the study. Sex distribution and age did not significantly differ between the test and placebo groups (Fig. 1). No adverse events or side effects were seen in any participants. For the Consort checklist, see Additional file 1.

General baseline characteristics for the 49 subjects were evaluated (Table 1). There were no significant differences between the two groups with respect to baseline values for age, BMI, waist diameter, waist-to-hip ratio, P-fat, lean body mass, and blood pressure (systolic and diastolic). When the subjects' parameters were compared before and after treatment, there were significant reductions in weight, $\mathrm{BMI}$, waist diameter, and $\mathrm{P}$-fat in the placebo group after 6 weeks. In the test group, weight and BMI significantly declined after the intervention compared with baseline values. However, these changes were not significantly different between the two groups. Total calorie intake (TCI), total energy expenditure (TEE), and dietary macronutrient intake did not significantly differ between the two groups at baseline. After the 6-week intervention, the placebo group showed significant increases in TEE and decreases in TCI compared with baseline. TCI was significantly reduced compared with baseline in the test group after the 6-week intervention. However, the net changes in these variables were not significantly different between the two groups (data not shown).

\section{Effect of arginyl-fructose supplementation on postprandial glucose metabolism}

Serum glucose levels at baseline and after the 6-week intervention in test and placebo groups are presented in

\section{CONSORT Flow Diagram}

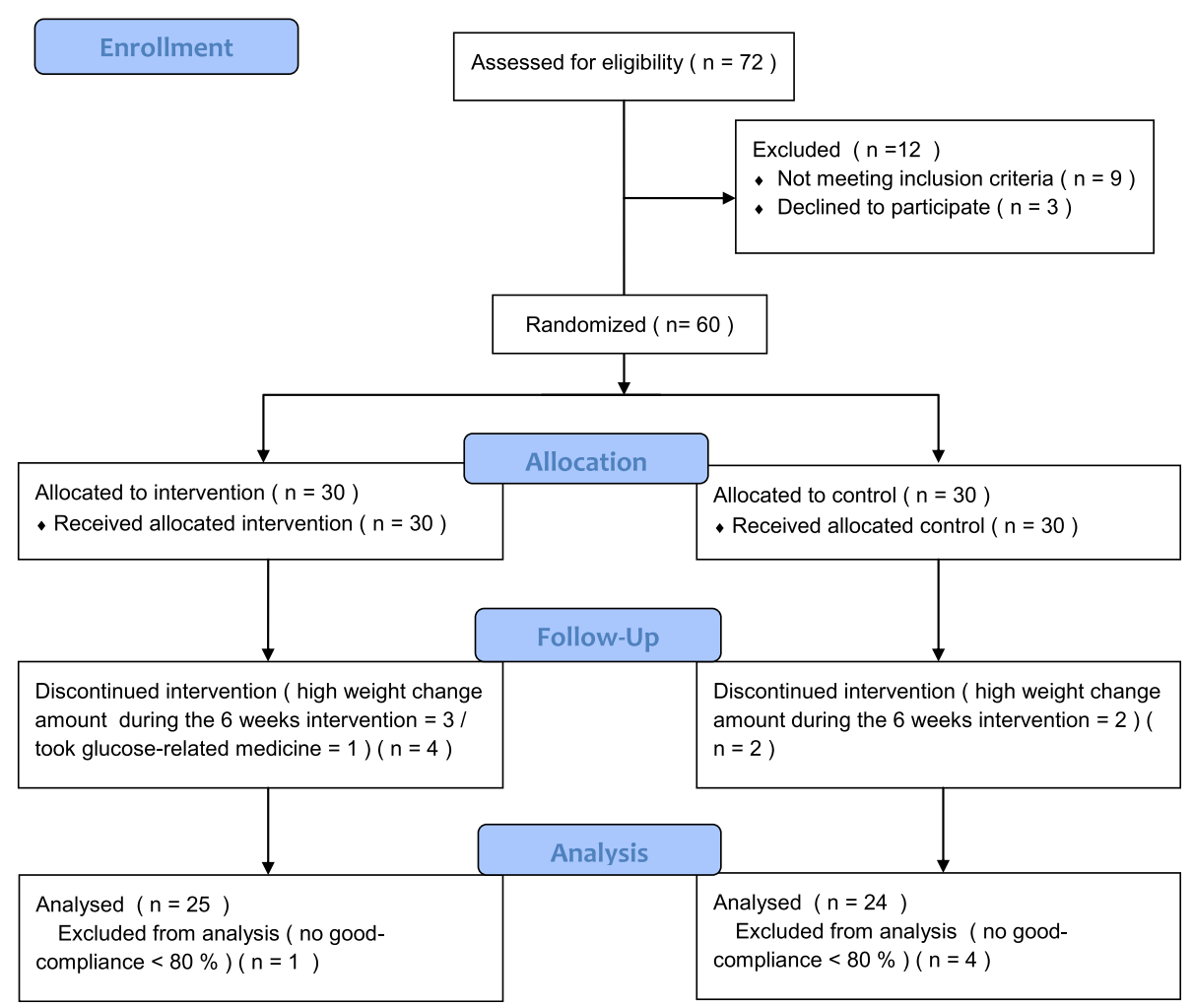

Fig. 1 Flow-chart of study randomization, allocation, follow-up, and analysis 
Table 1 Characteristics of study participants

\begin{tabular}{|c|c|c|}
\hline & Placebo $(n=24)$ & Test $(n=25)$ \\
\hline Age (years) & $58.3 \pm 1.27$ & $56.6 \pm 1.98$ \\
\hline Sex (male/female) & $(19 / 5)$ & $(19 / 6)$ \\
\hline \multicolumn{3}{|l|}{ Weight (kg) } \\
\hline 0 week & $65.9 \pm 2.25$ & $70.3 \pm 1.92$ \\
\hline 6 week & $65.3 \pm 2.25^{* *}$ & $69.67 \pm 1.86^{* *}$ \\
\hline \multicolumn{3}{|l|}{ BMI $\left(\mathrm{kg} / \mathrm{m}^{2}\right)$} \\
\hline 0 week & $23.4 \pm 0.67$ & $24.9 \pm 0.57$ \\
\hline 6 week & $23.2 \pm 0.67^{* *}$ & $24.7 \pm 0.55^{* *}$ \\
\hline \multicolumn{3}{|l|}{ WHR $(\mathrm{cm} / \mathrm{cm})$} \\
\hline 0 week & $0.89 \pm 0.01$ & $0.92 \pm 0.01$ \\
\hline 6 week & $0.89 \pm 0.01$ & $0.92 \pm 0.01$ \\
\hline \multicolumn{3}{|l|}{ Body fat (\%) } \\
\hline 0 week & $23.4 \pm 1.44$ & $26.1 \pm 1.45$ \\
\hline 6 week & $22.7 \pm 1.49^{* *}$ & $26.1 \pm 1.48$ \\
\hline \multicolumn{3}{|c|}{ Lean body mass (kg) } \\
\hline 0 week & $50.2 \pm 1.55$ & $51.9 \pm 2.94$ \\
\hline 6 week & $50.1 \pm 1.55$ & $51.3 \pm 1.57$ \\
\hline \multicolumn{3}{|l|}{ Systolic BP } \\
\hline 0 week & $128.6 \pm 2.67$ & $129.5 \pm 2.94$ \\
\hline 6 week & $124.5 \pm 2.99^{\dagger}$ & $128.2 \pm 2.17$ \\
\hline \multicolumn{3}{|l|}{ Diastolic BP } \\
\hline 0 week & $77.9 \pm 1.55$ & $78.2 \pm 1.85$ \\
\hline 6 week & $76.4 \pm 1.70$ & $78.2 \pm 1.57$ \\
\hline \multicolumn{3}{|l|}{ TEE (kcal/day) } \\
\hline 0 week & $2123 \pm 232.52$ & $2266 \pm 273.43$ \\
\hline 6 week & $2140 \pm 229.63^{*}$ & $2280 \pm 280.27$ \\
\hline \multicolumn{3}{|l|}{ TCl (kcal/day) } \\
\hline 0 week & $2241 \pm 251.81$ & $2288 \pm 261.65$ \\
\hline 6 week & $2210 \pm 261.45^{*}$ & $2266 \pm 252.84$ \\
\hline \multicolumn{3}{|l|}{ Carbohydrate (\%) } \\
\hline 0 week & $61.9 \pm 0.64$ & $61.3 \pm 0.81$ \\
\hline 6 week & $61.8 \pm 0.79$ & $61.3 \pm 0.77$ \\
\hline \multicolumn{3}{|l|}{ Protein (\%) } \\
\hline 0 week & $15.9 \pm 0.38$ & $16.0 \pm 0.37$ \\
\hline 6 week & $15.8 \pm 0.36$ & $15.9 \pm 0.38$ \\
\hline \multicolumn{3}{|l|}{ Fat (\%) } \\
\hline 0 week & $22.9 \pm 1.10$ & $23.4 \pm 1.25$ \\
\hline 6 week & $23.1 \pm 1.12$ & $23.4 \pm 0.87$ \\
\hline
\end{tabular}

Data are shown as mean \pm SEM

${ }^{+} p<0.1,{ }^{*} p<0.05,{ }^{* *} p<0.01$, compared to 0 week, tested by paired $t$-test $B M I$ Body mass index, BP Blood pressure, TCI Total calorie intake, TEE Total energy expenditure, WHR Waist-to-hip ratio
Table 2. After the intervention, the test group showed significant decreases in OGTT serum glucose levels at 30 minutes $(-19.4 \pm 5.62, p=0.002)$ and 60 minutes $(-15.4 \pm 7.01, p=0.035)$ and glucose area under the curve (AUC) $(-27.4 \pm 8.59, p=0.002)$. After the 6-week intervention, the placebo group showed a significant decrease in OGTT serum glucose levels at 30 minutes $(-14.3 \pm 5.24, p=0.015)$. After adjustment for baseline values, net changes in serum glucose levels at 60 minutes and glucose AUC in the test group were significantly larger than those in the placebo group after 6 weeks of AF intervention (Figs. 2 and 3).

\section{Levels of glucose-related biomarkers}

Glycosylated hemoglobin A1c (HbA1c) levels were significantly lower in test and control groups after the 6-week intervention compared with baseline values $(p=0.000$ and $p=0.007$, respectively). However, this change was not significantly different between the two groups. After the intervention, significant changes were observed in the test group serum insulin levels at 60 minutes $(p=0.010)$ and insulin AUC $(p=0.017)$ compared with baseline levels (Table 3). In the placebo group, serum insulin levels at 30 minutes $(p=0.012)$ and 60 minutes $(p=0.032)$ and insulin AUC $(p=0.003)$ significantly decreased compared with baseline after the intervention. There were also significant decreases in serum C-peptide levels at 30 minutes

Table 2 Oral glucose tolerance test serum glucose levels at baseline and after the 6-week intervention

\begin{tabular}{|c|c|c|}
\hline & Placebo $(n=24)$ & Test $(n=25)$ \\
\hline \multicolumn{3}{|c|}{ Glucose $(\mathrm{mg} / \mathrm{dL})^{\mathrm{a}}$} \\
\hline \multicolumn{3}{|l|}{0 minutes } \\
\hline 0 week & $114.0 \pm 2.50$ & $114.6 \pm 2.19$ \\
\hline 6 week & $120.4 \pm 3.54$ & $114.4 \pm 4.35$ \\
\hline \multicolumn{3}{|l|}{30 minutes } \\
\hline 0 week & $212.6 \pm 7.78$ & $197.9 \pm 8.11$ \\
\hline 6 week & $198.3 \pm 6.42^{*}$ & $178.6 \pm 7.36^{* *}$ \\
\hline \multicolumn{3}{|l|}{60 minutes } \\
\hline 0 week & $235.4 \pm 10.61$ & $209.3 \pm 11.70$ \\
\hline 6 week & $233.6 \pm 6.79$ & $194.0 \pm 11.59^{*}$ \\
\hline \multicolumn{3}{|c|}{120 minutes } \\
\hline 0 week & $196.6 \pm 12.01$ & $183.1 \pm 13.19$ \\
\hline 6 week & $187.5 \pm 8.68$ & $170.9 \pm 13.39$ \\
\hline \multicolumn{3}{|c|}{ Glucose AUC (mg/dL per hour $)^{a}$} \\
\hline 0 week & $409.7 \pm 15.61$ & $376.2 \pm 17.38$ \\
\hline 6 week & $398.2 \pm 11.14$ & $348.8 \pm 16.55^{* *}$ \\
\hline
\end{tabular}




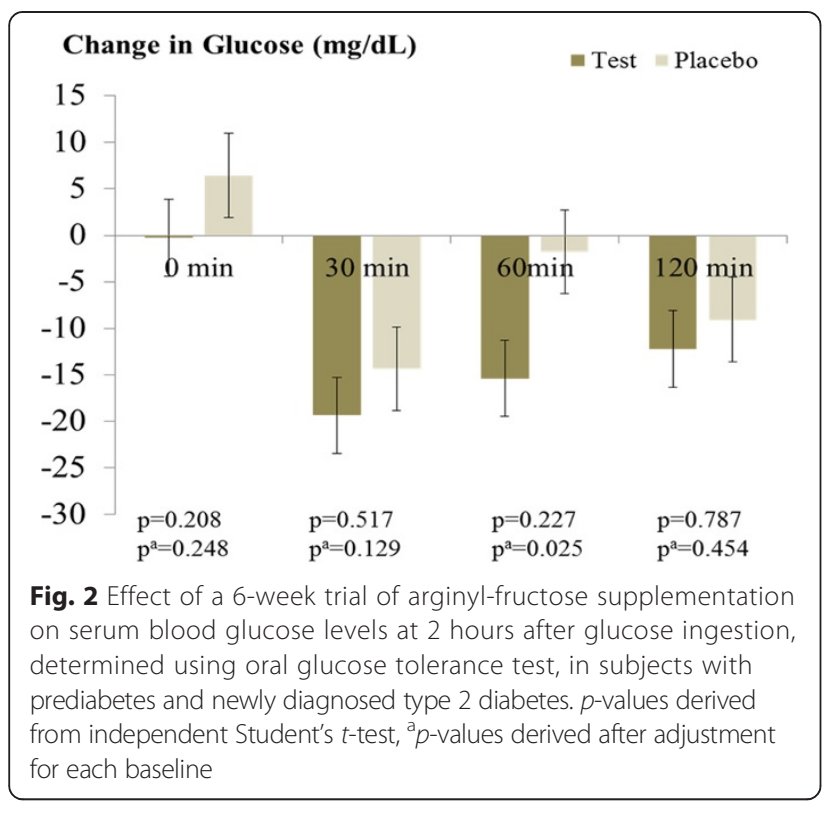

$(p=0.018)$ and 60 minutes $(p=0.025)$ and C-peptide AUC value $(p=0.044)$ in the placebo group. However, the net changes in these variables were not significantly different between the two groups.

\section{Lipid profiles and laboratory measurements}

No significant differences in the test and placebo groups were observed for serum lipid profiles. After the intervention, the serum albumin level significantly decreased in both groups. There were no significant differences in white blood cell counts, creatinine, blood urea nitrogen,

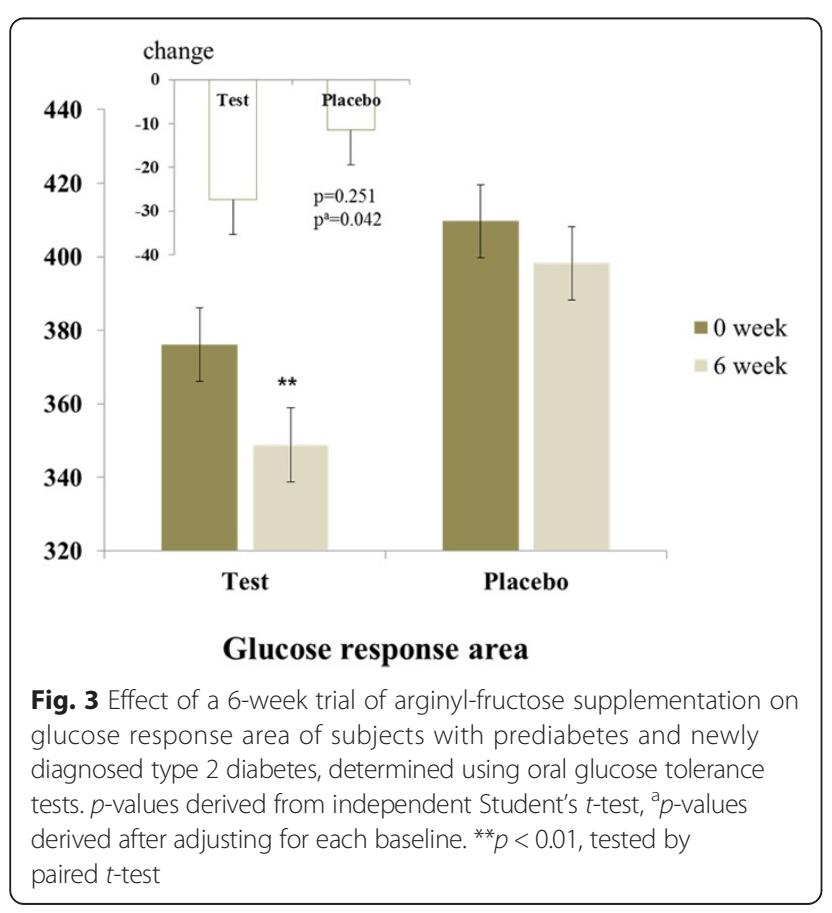

Table 3 Glucose-related biomarkers at baseline and after the 6-week intervention

\begin{tabular}{|c|c|c|}
\hline & Placebo $(n=24)$ & Test $(n=25)$ \\
\hline \multicolumn{3}{|c|}{ Hemoglobin A1c (\%) } \\
\hline 0 week & $6.4 \pm 0.16$ & $6.4 \pm 0.14$ \\
\hline 6 week & $6.2 \pm 0.14^{* * *}$ & $6.1 \pm 0.13^{* *}$ \\
\hline \multicolumn{3}{|c|}{ Insulin $(\mathrm{uU} / \mathrm{mL})^{\mathrm{a}}$} \\
\hline \multicolumn{3}{|l|}{0 minutes } \\
\hline 0 week & $9.5 \pm 0.77$ & $11.1 \pm 1.03$ \\
\hline 6 week & $9.2 \pm 0.68$ & $12.4 \pm 2.49$ \\
\hline \multicolumn{3}{|c|}{30 minutes } \\
\hline 0 week & $30.5 \pm 3.93$ & $43.7 \pm 8.26$ \\
\hline 6 week & $21.3 \pm 3.03^{*}$ & $41.3 \pm 8.60$ \\
\hline \multicolumn{3}{|c|}{60 minutes } \\
\hline 0 week & $44.5 \pm 6.35$ & $58.5 \pm 9.34$ \\
\hline 6 week & $34.9 \pm 5.06^{*}$ & $46.3 \pm 8.21^{*}$ \\
\hline \multicolumn{3}{|c|}{120 minutes } \\
\hline 0 week & $46.7 \pm 7.65$ & $56.1 \pm 10.58$ \\
\hline 6 week & $36.3 \pm 6.49^{\dagger}$ & $42.1 \pm 7.46^{\dagger}$ \\
\hline \multicolumn{3}{|c|}{ Insulin AUC (uU/mL per hour) ${ }^{a}$} \\
\hline 0 week & $74.3 \pm 8.66$ & $96.6 \pm 13.98$ \\
\hline 6 week & $57.3 \pm 7.72^{* *}$ & $79.5 \pm 11.74^{*}$ \\
\hline \multicolumn{3}{|c|}{ C-peptide $(\mathrm{ng} / \mathrm{mL})^{\mathrm{a}}$} \\
\hline \multicolumn{3}{|l|}{0 minutes } \\
\hline 0 week & $2.1 \pm 0.16$ & $2.5 \pm 0.18$ \\
\hline 6 week & $2.1 \pm 0.15$ & $2.7 \pm 0.33$ \\
\hline \multicolumn{3}{|l|}{30 minutes } \\
\hline 0 week & $5.1 \pm 0.38$ & $6.0 \pm 0.60$ \\
\hline 6 week & $4.4 \pm 0.39^{*}$ & $5.9 \pm 0.71$ \\
\hline \multicolumn{3}{|l|}{60 minutes } \\
\hline 0 week & $7.5 \pm 0.49$ & $8.6 \pm 0.75$ \\
\hline 6 week & $6.8 \pm 0.47^{*}$ & $8.0 \pm 0.68$ \\
\hline \multicolumn{3}{|c|}{120 minutes } \\
\hline 0 week & $9.4 \pm 0.67$ & $9.1 \pm 0.69$ \\
\hline 6 week & $9.2 \pm 0.65$ & $8.4 \pm 0.64$ \\
\hline \multicolumn{3}{|c|}{ C-peptide AUC $(\mathrm{ng} / \mathrm{mL})^{a}$} \\
\hline 0 week & $13.4 \pm 0.79$ & $14.6 \pm 1.10$ \\
\hline 6 week & $12.4 \pm 0.83^{*}$ & $13.8 \pm 1.01$ \\
\hline
\end{tabular}

Data are shown as mean \pm SEM

${ }^{+} p<0.1,{ }^{*} p<0.05,{ }^{* *} p<0.01,{ }^{* * *} p<0.001$ compared to 0 week, tested by paired $t$-test

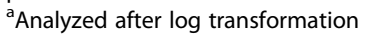

AUC Area under the curve

serum glutamic oxaloacetic transaminase, serum glutamatepyruvate transaminase, or high-sensititvity $\mathrm{C}$ reactive peptide within each group before and after the intervention (data not shown). 


\section{Discussion}

This study determined the effects of 6 weeks AF supplementation on glucose control in 49 Korean subjects with prediabetes and newly diagnosed T2DM. After the intervention, the test group showed significant decreases in OGTT serum glucose levels at 30 and 60 minutes and glucose AUC. After adjusting for baseline levels, the changes (differences from baseline) in OGTT serum glucose levels at 60 minutes and glucose response areas in the AF intervention group were significantly different from those in the placebo group. These results indicate that AF supplementation for 6 weeks may have beneficial effects for reducing postprandial blood glucose levels in individuals with IFG, IGT, or newly diagnosed T2DM. The AF content in KRG is relatively high. This compound is formed from $\mathrm{L}$-arginine plus glucose or maltose via a Maillard reaction that occurs during commercial processing of raw ginseng to produce the dried red ginseng product [5].

Previous studies reported that AF and AFG have strong and similar sucrase inhibitor activity. Ha et al. reported that AF had an antihyperglycemic effect and inhibited postprandial hyperglycemia in vitro and in vivo [8]. They demonstrated that AF has strong sucrase and $\alpha$-amylase inhibitory activity in vitro. The carbohydrate hydrolyzing enzymes $\alpha$-amylase and $\alpha$-glucosidase regulate glucose digestion and absorption. Therefore, a therapeutic approach to inhibit postprandial hyperglycemia is to inhibit the activity of these enzymes using $\alpha$-glucosidase inhibitors such as acarbose $[17,18]$. In an animal model, AF significantly reduced postprandial blood glucose levels after starch or sucrose loading in Sprague-Dawley rats. These results indicate that AF may exert antidiabetic effects by suppressing carbohydrate absorption in the gastrointestinal tract, and thereby reduce the postprandial increase in blood glucose levels [8]. The latest study from the same authors (2014) evaluated whether AF could lower blood glucose levels in $\mathrm{db} / \mathrm{db}$ mice (T2DM model), and the results and conclusions were similar [19]. The administration of AF for 42 days with high carbohydrate diets decreased fasting blood glucose levels, HbA1c concentrations, and total body weight. These reductions were similar to those observed after acarbose treatment, and were significantly lower than controls $(p<0.001)$. These results indicate that AF effectively manages hyperglycemia. Therefore, this trial provides evidence in support of potential therapeutic applications of AF to control T2DM.

The antioxidant activities of AF and AFG were investigated previously; these compounds exhibited strong radical scavenging activities. AF has greater radical scavenging activity for hydroxyl radical and DPPH than AFG [20,21]. This result was similar to a previous study, which proposed that the Maillard reaction products AF and AFG could be valuable materials for the development of nutraceutical food with antioxidant activity [11].

Our study is the first clinical trial of AF supplementation for controlling postprandial hyperglycemia in prediabetic and newly diagnosed T2DM subjects. The randomized controlled trial enrolled Korean adult subjects, and determined that AF supplementation may reduce postprandial glucose levels. Our study has some limitations. The trial had a relatively short 6-week duration and enrolled a small number of participants. In addition, the screening criteria for determining if subjects were prediabetic or newly diagnosed T2DM were quite broad. Therefore, further study is needed using a larger number of participants for a longer time with subjects who have IGT or IFG alone. For future large-scale studies, additional testing is needed to optimize AF supplementation dosages and glucose control.

\section{Conclusions}

Our study determined the effects of 6 weeks AF supplementation on glucose control in 49 Korean subjects with prediabetes and newly diagnosed T2DM. After the 6-week intervention, the test group showed significant reductions in serum glucose levels at 30 minutes $(-19.4 \pm 5.62 \mathrm{mg} / \mathrm{dL})$ and 60 minutes $(-15.4 \pm 7.01 \mathrm{mg} / \mathrm{dL})$ and reduced glucose AUC $(-27.4 \pm 8.59 \mathrm{mg} / \mathrm{dL})$ compared with those of the placebo control group. The changes (differences from baseline) in serum glucose levels at 60 minutes and glucose AUC in the test group differed significantly from those in the control group even after adjusting for baseline values. In conclusion, AF supplementation $(1500 \mathrm{mg} /$ day $)$ may be beneficial for reducing postprandial blood glucose levels in patients with prediabetes or T2DM.

\section{Additional file}

Additional file 1: CONSORT Checklist. (DOC $60 \mathrm{~kb}$ )

\section{Abbreviations}

AF: Arginyl-fructose; AFG: Arginyl-fructose-glucose; apo: Apolipoprotein; AUV: Area under the curve; BMI: Body mass index; HbA1c: Hemoglobin A1c; HDL: High-density lipoprotein; IFG: Impaired fasting glucose; IGT: Impaired glucose tolerance; KRG: Korean red ginseng; LDL: Low-density lipoprotein; OGTT: Oral glucose tolerance test; T2DM: Type 2 diabetes mellitus; TCl: Total calorie intake; TEE: Total energy expenditure; TG: Triglyceride.

\section{Competing interests}

The authors declare that they have no competing interests.

\section{Authors' contributions}

SEP and OHK conducted the research, analyzed the data, and wrote the paper. JHK designed the study, analyzed the data, and reviewed/edited the manuscript. KHL and YIK contributed to data collection. JHL and KHC supervised the study. All authors approved the final manuscript for submission.

\section{Acknowledgements}

This work was supported by the INNOPOLIS Daedeok Foundation grant (A2012-DD-002) and the Bio \& Medical Technology Development Program (NRF-2012M3A9C4048762) of the National Research Foundation (NRF), which 
is funded by the Ministry of Science, ICT \& Future Planning, Republic of Korea.

\section{Author details}

'Department of Food and Nutrition, National Research Laboratory for Clinical Nutrigenetics/Nutrigenomics, Yonsei University, Seoul 120-749, Republic of Korea. ${ }^{2}$ Research Institute of Science for Aging, Yonsei University, Seoul 120-749, Republic of Korea. ${ }^{3}$ R\&D Center, CHA BioMed and Department of Applied Science, CHA University, Gyeonggi-do 463-836, Republic of Korea. ${ }^{4}$ Department of Food and Nutrition, Hannam University, Daejeon 305-811, Republic of Korea.

Received: 9 February 2015 Accepted: 27 October 2015

Published online: 14 November 2015

\section{References}

1. Basu S, Yoffe P, Hills N, Lustig RH. The relationship of sugar to population-level diabetes prevalence: an econometric analysis of repeated cross-sectional data. PLoS One. 2013;8:e57873.

2. Wild S, Roglic G, Green A, Sicree R, King H. Global prevalence of diabetes_estimates for the year 2000 and projections for 2030. Diabetes Care. 2004:27:1047-53.

3. Ministry of Health and Welfare. The fifith Korea national health and nutrition examination survey (KNHANES V), Seoul, Republic of Korea. 2012. p. 56-7.

4. Kwak YS, Park JD, Yang JW. Present and its prospect of red ginseng efficacy research. Food Ind Nutr. 2003:8:30-7.

5. Suzuki Y, Choi KJ, Ko SR, Soha HJ, Park JD. Arginyl-fructosyl-glucose and arginyl-fructose, compounds related to browning reaction in the model system of steaming and heat-drying processes for the preparation of red ginseng. J Ginseng Res. 2004;28:143-8.

6. Matsuura Y, Zheng Y, Takaku T, Kameda K, Okuda H. Isolation and physiological activities of a new amino acid derivative from Korean red ginseng. Korean J Ginseng Sci. 1994;18:204-11.

7. Nam KY. The comparative understanding between red ginseng and white ginsengs, processed ginsengs (Panax ginseng C.A Meyer). J Ginseng Res. 2005;29:1-18.

8. Ha KS, Jo SH, Kang BH, Apostolidis E, Lee MS, Jang HD, et al. In vitro and in vivo antihyperglycemic effect of 2 amadori rearrangement compounds, arginyl-fructose and arginyl-fructosyl-glucose. J Food Sci. 2011;76:188-93.

9. Joo KM, Park CW, Jeong HJ, Lee SJ, Chang IS. Simultaneous determination of two Amadori compounds in Korean red ginseng (Panax ginseng) extracts and rat plasma by high-performance anion-exchange chromatography with pulsed amperometric detection. J Chromatography B. 2008;865:159-66.

10. Yoon SR, Lee GD, Park JH, Lee IS, Kwon JH. Ginsenoside composition and antiproliferative activities of explosively puffed ginseng (panax ginseng C.A. Meyer). J Food Sci. 2010;75:378-82.

11. Lee JS, Kim GN, Lee SH, Kim ES, Ha KS, Kwon Yl, et al. In vitro and cellular antioxidant activity of arginyl-fructose and arginyl-fructosyl-glucose. Food Sci Biotechnol. 2009;18:1505-10.

12. Bang HJ, Kwak JH, Ahn HY, Shin DY, Lee $J H$. Korean Red ginseng improves glucose control in subjects with impaired fasting glucose, impaired glucose tolerance, or newly diagnosed type 2 diabetes mellitus. J Med Food. 2014;17:128-34

13. Kim HJ, Ahn HY, Kwak JH, Shin DY, Kwon YI, Oh CG, et al. The effects of chitosan oligosaccharide (GO2KA1) supplementation on glucose control in subjects with prediabetes. Food Funct. 2014;5:2662-9.

14. Shim JS, Oh KW, Suh I, Kim MY, Shon CY, Lee EJ, et al. A study on validity of a 299 semiquantitative food frequency questionnaire of Korean adults. Kor J Community Nutr. 2002;7:484-94.

15. Christian JL, Greger JL. Nutrition for living. Redwood: Benjamin/Cummings; 1994. p. 111.

16. The American Dietetic Association. Handbook of clinical dietetics. 2nd ed. New Haven: Yale University Press; 1992. p. 5-39.

17. Lebovitz HE. Alpha-glucosidase inhibitors. Endocrinol Metab Clin N Am. 1997;26:539-51.

18. Van de Laar FA, Lucassen PLBJ, Akkermans RP, Van de Lisdonk EH, Rutten GEHM, Van Weel C. Alpha-glucosidase inhibitors for type 2 diabetes mellitus. Cochrane Database Syst Rev. 2005;8:CD003639.

19. Lee KH, Ha KS, Jo SH, Lee CM, Kim YC, Chung KH, et al. Effect of long-term dietary arginyl-fructose (AF) on hyperglycemia and $\mathrm{HbA} 1 \mathrm{c}$ in diabetic $\mathrm{db} / \mathrm{db}$ mice. Int J Mol Sci. 2014;15:8352-9.
20. Gao FF, Zhang WY, Liu LM, Chang C, Han LK, Wei HY, et al. Detection and distribution of arginine derivatives in Panax quinquefolius $L$. and investigations of their antioxidant properties. Food Sci Technology. 2012:49:34-41.

21. Kim GN, Lee JS, Song JH, Oh CH, Kwon Yl, Jang HD. Heat processing decreases amadori products and increases total phenolic content and antioxidant activity of Korean red ginseng. J Med Food. 2010;13:1478-84

\section{Submit your next manuscript to BioMed Central and take full advantage of:}

- Convenient online submission

- Thorough peer review

- No space constraints or color figure charges

- Immediate publication on acceptance

- Inclusion in PubMed, CAS, Scopus and Google Scholar

- Research which is freely available for redistribution

Submit your manuscript at www.biomedcentral.com/submit 